\section{How Target Therapy can Induce Cardiotoxicity: The Onco-Cardiologist Point of View}

Joana Espiga de Macedo, MD*

Consultant of Medical Oncologist, Department of Medical Oncology, Centro Hospitalar de Entre, Douro e Vouga, Portugal

\section{INTRODUCTION}

The life expectancy of an oncological patient has been increased significantly decades due to the evolution of cancer therapies. The aim of this paper is to review how these new target molecules, which have a direct impact on the cancer cell as opposed to the classical chemotherapy, known to all of us for a long time. How do they act specifically? What are their cardiotoxic effects at a short and long time period? How can they be monitored? How can they be prevented and treated? And above all, how can we prevent an oncological patient to become a cardiovascular one later on, due to induced cardiotoxicity caused by oncological therapies. We have to treat our patients as a whole and not only, target therapy to one of the pieces of the puzzle.

\section{DEFINITION}

Cardiotoxicity can be defined as all damage caused directly or indirectly to the cardiomyocyte. This is a broad term which affects the cardiovascular system in many ways. The classical definition refers a reduction in left ventricular ejection fraction and the development of heart failure. ${ }^{1}$ However, they can be divided in ten categories: myocardial dysfunction, heart failure, coronary artery disease, arrhythmias, arterial hypertension, thromboembolic disease, peripheral vascular disease, stroke, pulmonary hypertension and pericardial complications (Figure 1).

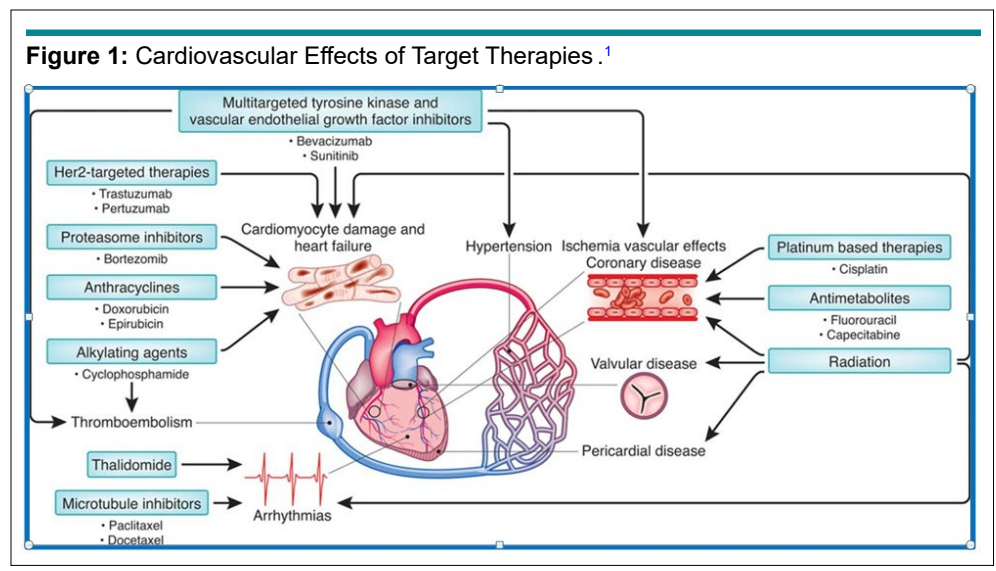

First of all, when a patient presents himself with a certain lifestyle risk factors (smoking, alcohol, obesity), demographic and other cardiovascular risk factors (age, arterial hypertension or diabetes mellitus) then it is needed to be checked whether the factors are known or unknown, treated and controlled or not. Depending on past history, he may also have cardiovascular disease such as heart failure or myocardial infarct. Or he might even, have already have had, a primary cancer diagnose and submitted to chemotherapy or radiotherapy previously. 
As mentioned above, the three most important cardiotoxicities are myocardial dysfunction, heart failure and coronary artery disease. The mechanisms of action of these target therapies and how they act and their statistical incidence can be analysed in Tables 1 and 2. However, as already mentioned, in Table 3 , we can evaluate the population baseline cardiovascular risk factors, which may be increased by specific target therapies as will be explained further on.

\section{HUMAN EPIDERMAL RECEPTOR 2 (HER2)}

Human epidermal receptor 2 (HER2), is a member of the ErbB protein family, with an extracellular domain and an intracellular domain. It is overexpressed for example, in patients with breast cancer. It is an extremely important control centre of unregulated cell growth and proliferation. Blocking this protein by target therapies, leads to inhibitionor downregulation of the

\begin{tabular}{|cccc}
\hline \multicolumn{4}{|c|}{ Table 1: Heart Failure and Myocardial Dysfunction. } \\
\hline Agent & Incidence (\%) & Agent & Incidence (\%) \\
\hline Doxorubicin & $2-48$ & Pertuzumab & $<1.5$ \\
\hline Epirubicin & $1-3.3$ & Lapatinib & $<1$ \\
\hline Lipsomal A & 2 & Sunitinib & $2.7-19$ \\
\hline Cyclophosphamide & $7-28$ & Sorafenib & $4-8$ \\
\hline Ifosfamide & 17 & Pazopanib & $7-11$ \\
\hline Docetaxel & $2-13$ & Imatinib & $<3$ \\
\hline Paclitaxel & $<1$ & Everolimus & $<1$ \\
\hline Bevacizumab & $1.6-4$ & Temsirolimus & $<1$ \\
\hline Trastuzumab & $1.7-20$ & & \\
\hline
\end{tabular}

\begin{tabular}{|c|c|c|}
\hline Therapies & Possible mechanisms & Incidence \\
\hline $\begin{array}{l}\text { Fluoropyrimidines } \\
\text { (5-FU, capecitabine) }\end{array}$ & Endothelial injury and vasospasm & $\begin{array}{l}\text { Myocardial ischemia: } 18 \% \\
\text { Silent myocardial ischemia: } 50 \%\end{array}$ \\
\hline Platinum salts & $\begin{array}{l}\text { Procoagulant status; arterial } \\
\text { thrombosis }\end{array}$ & $\begin{array}{c}\text { Thrombosis: } 2 \% \\
\text { In long-term survivors ( } 8 \% 20 \text { y testicular cancer) }\end{array}$ \\
\hline VEGF inhibitors & $\begin{array}{l}\text { Procoagulant status; arterial } \\
\text { thrombosis; endothelial injury }\end{array}$ & AT with bevacizumab $3.8 \%$ \\
\hline Radiotherapy & $\begin{array}{l}\text { Thrombosis; endothelial injury, plaque rupture } \\
\qquad 30 \mathrm{y}\end{array}$ & $\begin{array}{c}\text { In long-term survivors } \\
(13 \% 30 \text { y Hodgkin lymphoma) }\end{array}$ \\
\hline
\end{tabular}

\begin{tabular}{|c|c|}
\hline Agent & Risk factors \\
\hline \multicolumn{2}{|l|}{ Anti-HER2 compounds } \\
\hline $\begin{array}{l}\text { Antibodies } \\
\text { - Trastuzumab } \\
\text { - Pertuzumab } \\
\text { - T-DM1 } \\
\text { Tyrosine Kinase inhibitors } \\
\text { - Lapatinib }\end{array}$ & $\begin{array}{l}\text { - Previous or concomitant anthracycline treatment (short time } \\
\text { between anthracycline and anti-HER2 treatment) } \\
\text { - Age ( }>65 \text { years) } \\
\text { - High BMI }>\mathrm{kg} / \mathrm{mg}^{2} \\
\text { - Previous LV dysfunction } \\
\text { - Arterial hypertension } \\
\text { - Previous radiation therapy }\end{array}$ \\
\hline \multicolumn{2}{|l|}{ VEGF inhibitors } \\
\hline $\begin{array}{l}\text { Antibodies } \\
\text { - Bevacizumab } \\
\text { - Ramucirumab }\end{array}$ & $\begin{array}{l}\text { - Pre-existing HF, significant CAD or left side VHD (e.g. mitral } \\
\text { regurgitation), chronic ischaemic cardiomyopathy } \\
\text { - Previous anthracycline }\end{array}$ \\
\hline $\begin{array}{l}\text { Tyrosine Kinase inhibitors } \\
\text { - Sunitinib } \\
\text { - Pazopanib } \\
\text { - Axitinib } \\
\text { - Neratinib } \\
\text { - Afatinib } \\
\text { - Sorafenib } \\
\text { - Dasatinib }\end{array}$ & $\begin{array}{l}\text { - Arterial hypertension } \\
\text { - Pre-existing cardic disease }\end{array}$ \\
\hline
\end{tabular}


phosphoinositide 3-kinase (P13-Kinase/AKT) and the mitogenactivated protein kinase (MAPK/ERK1/2) pathways (Figure 2). ${ }^{2}$

This protein can be inhibited in two places: in the extracellular domain by trastuzumab, a monoclonal antibody, or in the intracellular domain by lapatinib, an inhibitor of the receptor of the tyrosine kinase domain. This leads to downregulation of this pathway. Consequently, leading to impaired myocardial response to stress, leading to hypertension.

By blocking the extracellular domain this inhibitor starts competing with neuregulin-1 (NRG-1) which is released by the endothelial cells. It has an autocrine function, stimulating angiogenesis and vascular homeostasis, and also a paracrine effect, acting on the myocyte leading to growth, survival and maintenance of the sarcomere organisation by stimulating the erbB2 pathway. Together these effects protect the cardiac structure and function under normal conditions. It has a cardio-protective effect. However if this pathway is blocked, it induces apoptosis leading to heart failure. On the other hand, if tyrosine signalling is maintained, with constant stimulation by neuregulin-1, preservation of the myocyte haemostasis is achieved. ${ }^{2}$

\section{VASCULAR ENDOTHELIAL GROWTH FACTOR (VEGF) AND PLATELET DERIVED GROWTH FACTOR (PDGF)}

Inhibition of the VEGF may occur in different places along the signalling pathway. Directly, on the ligand for example as dose bevacizumaba monoclonal antibody. It blocks its connection to the VEGF receptor (VEGFR). Secondly, by blocking the receptor directly as does Sunitinib. It doesn't allow an adaptative modulation of vascular structure and function, leading to hypertension and left ventricle disfunction. Sunitinib blocks the AMP-activated protein kinase (AMPK) pathway disrupting the regulation of the endothelial metabolism (Figure 3).

PDGF can also be blocked in the intracellular domain of the PDGF receptor (PDGFR) by Sorafenib, a tyrosine kinase inhibitor, which causes disruption of the cardiomyocyte haemostasis leading to hypertension.
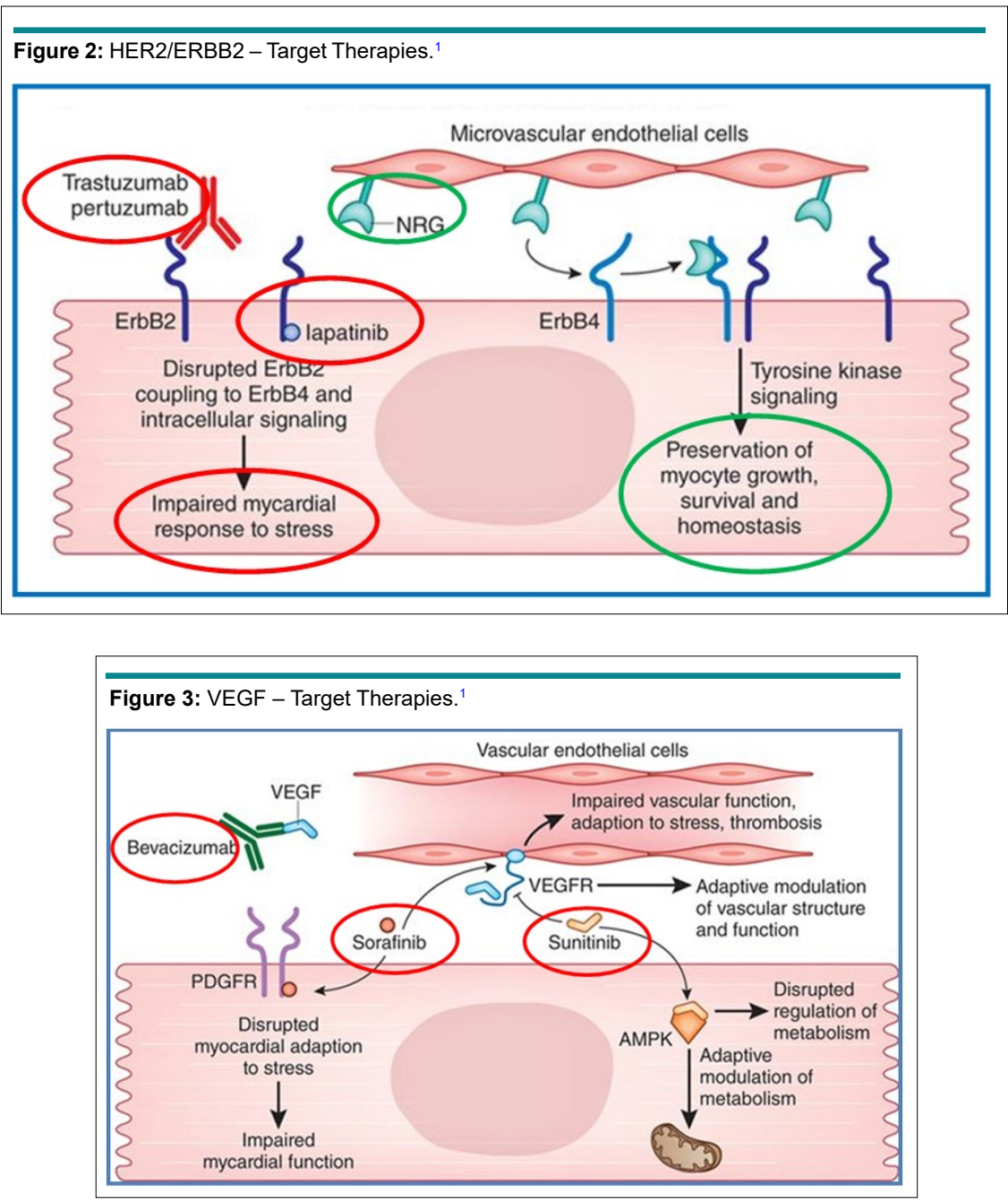


\section{HOW CAN THESE CARDIOVASCULAR TOXICITIES BE MONITORED, PREVENTED AND TREATED?}

First of all, a rigorous screening can be done to exclude patients at unacceptable high cardiovascular risk. This is achieved with a complete patient's history, physical examination, alerted to signs and symptoms of heart failure. Evaluate cardiac co-morbidities and if it was well medicated and controlled. Also patients should be questioned regarding previous cancer history and therapies performed, if any.

Secondly, it is necessary to adapt each treatment to the patient we have in front, and induce less toxicity as possible in all areas. Regular screening can be done by echocardiography with Doppler imaging to evaluate the left ventricle ejection fraction. It is still the standard of care, which best characterizes the cardiac morphology and function, detects cardiac systolic and diastolic dysfunction, although it's operator dependent and time consuming. On the other hand it doesn't expose the patient to radiation as multi-gated acquisition (MUGA). Cardiac magnetic resonance imaging (MRI) it's not widely available, causes claustrophobia and is expensive comparing theechocardiography with Doppler imaging. ${ }^{3}$

Cardiac biomarkers, such as brain natriuretic peptide (BNP) and troponin I (TNT) have been wildly used in many trials, but have never been validated as true biomarkers. ${ }^{3}$ However, it has been demonstrated that TNT early increase and detection, is predictive of early cardiac dysfunction in oncological patients. Consequently, early treatment with inhibition of the angiotensin converting enzyme, may avoid late dysfunction of the left ventricle. When early cardiomyopathy cell death is detected both present elevated parameters. ${ }^{4,5}$

Treatment has long been more beneficial and effective, when it is started as early as possible with cardioprotective drugs. The most common used are $\beta$-blockers and inhibition of the angiotensin converting enzyme pathway (ACE). Also correction and control of other co-morbidities are also extremely important to prevent further damage to the cardiomyocyte. Adopt healthy lifestyle is essential in all medical areas, such as: a healthy diet, not smoking controlling body weight and above all regular aerobic exercise.

\section{FUTURE ORIENTATIONS}

Clinicians have to be more aware of heart disease in oncological patients and survivors. The aim of this paper was to widen the view of how these new targeting molecules may act on the cardiovascular system, what's the best way to diagnose and prevent and also how to treat. More than ever, efforts between cardiologists who best know how to deal with cardiovascular disease, in its differentclinical ways, the oncologist who best deals with the targeting therapies and its consequences and also, the family physician who has the best knowledge of the patient's clinical history and co-morbidities. It depends on the fusion of these essential practitioners that they can best treat the patient as whole, with the best quality of life (QoL). Nevertheless, larger prospective studies are needed to validate appropriate methods of monetarization, prevention and treatment of cardiovascular effects of cancer target therapies.

\section{REFERENCES}

1. Lenneman CG, Sawyer DB. Cardio-oncology an update on cardiotoxicity of cancer-related treatment. Circ Res. 2016; 118: 1008-1020. doi: 10.1161/CIRCRESAHA.115.303633

2. Hahn VS, Lenihan L, Ky B. Cancer therapy-induced cardiotoxicity: Basic mechanisms and potential cardioprotective therapies virginia shalkey. J Am Heart Assoc. 2014; 3(2): e000665. doi: 10.1161/JAHA.113.000665

3. Zamorano JL, Lancellotti P, Muñoz DR, et al. 2016 ESC Position Paper on cancer treatments and cardiovascular toxicity developed under the auspices of the ESC Committee for Practice Guidelines The Task Force for cancer treatments and cardiovascular toxicity of the European Society of Cardiology (ESC). Eur Heart J. 2016; 37: 2768-2801. doi: 10.1093/eurheartj/ehw211

4. Cardinale D, Colombo A, Lamantia G, et al. Anthracyclineinduced cardiomyopathy: Clinical relevance and response to pharmacologic therapy. J Am Coll Cardiol. 2010; 55(3): 213220. doi: 10.1016/j.jacc.2009.03.095

5. Cardinale D, Colombo A, Sandri MT, et al. Prevention of high-dose chemotherapy-induced cardiotoxicity in high-risk patients by angiotensin-converting enzyme inhibition. Circulation. 2006; 114: 2474-2481. doi: 10.1161/CIRCULATIONAHA.106.635144 